\title{
CONTROL OF GLYCEMIA AND CARDIOVASCULAR RISK FACTORS IN PATIENTS WITH TYPE 2 DIABETES IN PRIMARY CARE IN MONTENEGRO
}

\author{
Milena M. Cojić ${ }^{1,2}$, Ljiljana Cvejanov-Kezunović ${ }^{1,2}$, Jelena Stanković \\ Nebojša Kavarić ${ }^{2}$, Maja Koraćević ${ }^{3}$, Ljiljana Damjanović ${ }^{4}$ \\ ${ }^{1}$ Medical Faculty Podgorica, University of Montenegro, Montenegro \\ ${ }^{2}$ Primary Health Center Podgorica, Montenegro \\ ${ }^{3} \mathrm{PhD}$ student of Pharmaceutical sciences at Medical Faculty, University of Niš, Serbia \\ ${ }^{4} \mathrm{PhD}$ student of Medical sciences at Medical Faculty, University of Niš, Serbia
}

\begin{abstract}
Some observational studies have shown that only a small number of diabetic patients achieve optimum control of glycaemia and cardiovascular risk factors. The aim of this study was to analyze whether patients with type 2 diabetes mellitus treated in primary care achieve adequate control of glycemic levels and cardiovascular risk factors. This was a retrospective, record-based, cross-sectional study that included eligible patients from 35 to 90 years old with type 2 diabetes mellitus treated in Primary Health Care Center in Podgorica. We investigated electronic records of 531 diabetic patients. The observed prevalence of type 2 diabetes mellitus among individuals between ages 35 and 90 years, was 11,84\%. Half of the patients were female. The mean age was $65,88 \pm 9,86$ years. The mean value of $\mathrm{HbAlc}$ was 7,56 $\pm 1,71$. Fifty-nine percents of patients achieved optimal levels of HbAlc $\leq 7 \%$. Also, more than half of patients achieved target levels of blood pressure while 27.9\% achieved $L D L \leq 2.6 \mathrm{mmol} / \mathrm{L}$. Fifty percent of patients were non-smokers and $45.1 \%$ were obese. Among patients on primary prevention only $5.7 \%$ had met all target levels while on secondary prevention that number was even smaller $3.7 \%$. Our study showed that control of HbAlc and blood pressure was similar to other studies but reaching target levels of LDL was challenging for our patients. Further analysis are needed in order to discover the reasons for poor control of certain CVRF and to develop strategies for its optimal management.
\end{abstract}

Key words: diabetes mellitus type 2, management, risk factors, targets.

\section{Introduction}

Diabetes mellitus is a serious, chronic disease with an overall estimated prevalence of $8.5 \%$ in Europe [1]. More than $85 \%$ of diabetic patients suffer from type 2 diabetes mellitus (T2DM) which usually occurs later in life [2]. In $50 \%$ of cases T2DM remains undiagnosed and untreated for some period of time leading to serious chronic complications at the time of diagnosis [3].

Cardiovascular disease (CVD) is one of the most important complications in diabetic patients that reduces the quality of life and causes premature death. Several studies have shown that the risk of developing CVD in diabetic patients is 2 to 3 times higher than in patients with normal blood glucose levels [4]. CVD is also the most prevalent cause of death in diabetic patients mostly due to an increased risk of stroke and myocardial infarction [5]. This represents a major public health burden, so prevention and the adequate treatment of this disease is a priority for health systems.

Correspondence to: Milena M. Cojić, M.D.

Medical Faculty Podgorica, University of Montenegro,

bb Ljubljanska Str., 81000 Podgorica, Montenegro

Phone: +38269160909

E-mail: milenarovcanin@yahoo.com

Received February $13^{\text {th }}, 2018$, Accepted May $23^{\text {rd }}, 2018$
The existence of national and international guidelines for the management of the patients with diabetes has eased the care for these patients and set the standards for their treatment. In 2017 American diabetes association (ADA) has issued the guidelines in which special emphasis is placed on the field of work of family physicians. They should have one of the most important roles in adequate caring for diabetic patients because adequate metabolic control and control of cardiovascular risk factors (CVRF) can prevent or slow down CVD in these patients [6]. Unfortunately, some observational studies have shown that there has been a discrepancy between official recommendations and everyday practice, and that only $7-14 \%$ of patients with diabetes achieve optimum control of CVRF $[7,8]$.

The aim of this study was to analyze whether patients with T2DM treated in Primary Health Care Center in Podgorica achieve adequate control of glycemic levels and CVRF.

\section{Subjects and Methods}

This was a record-based cross-sectional study that included eligible patients with T2DM treated in Primary Health Care Center in Podgorica which is the main primary health care provider in Montenegro. According to the data that researchers got from National Health Insurance Fund, this 
Primary Health Care Center operates with 119444 insurance covered citizens aged 35 to 90 years and 14144 of them have T2DM. They are all registered with a general practitioner/family doctor. We analyzed 531 electronic records of randomly selected patients who have been diagnosed with T2DM (International Classification of Diseases 10 [ICD-10] codes E11 and E14) before January 12016 . For every patient we collected following data that have been recorded until the end of March 2017: age; sex; time since diagnosis; the presence of: retinopathy (ICD-10 codes E11.3 and H36.0); neuropathy (ICD-10 code G63.2); nephropathy (ICD code E11.21 or estimated glomerular filtration rate [GFR] with the MDRD [modification of diet in renal disease] formula [9] based on the most recent serum creatinine level recorded over the previous 15 months); coronary artery disease (ICD-10 codes I20, I21, I22, I23 and I24); stroke (ICD-10 codes I63, I64, G45 and G46), peripheral arterial vessel diseases (ICD-10 code I73.9) and chronic heart failure (ICD-10 code I50). We also collected data about glycemic control (the most recently recorded values of glycosylated hemoglobin [HbA1c] over the previous 15 months) and control of the CVRF - the most recently reported body mass index (BMI) over the previous 36 months; mean values of systolic (SBP) and diastolic blood pressure (DBP) over the previous 12 months; smoking status; the most recently recorded levels of total cholesterol (TC), triglyceride (TG), low-density lipoprotein (LDL), and high-density lipoprotein (HDL) over the previous 12 months.

In order to asses whether they have achieved control of glycemic levels and CVRF we used current ADA guidelines and European guidelines on cardiovascular disease prevention $[6,10]$. Target levels for glycemic control was HbAlc $\leq 7 \%$ and for CVRF: $\mathrm{BP} \leq 140 / 85$, $\mathrm{TC} \leq 5,0 \mathrm{mmol} / \mathrm{L}, \mathrm{TG} \leq 1,7, \mathrm{HDL} \geq 1,0 \mathrm{mmol} / \mathrm{L}$ for men and $\geq 1,2 \mathrm{mmol} / \mathrm{L}$ for women, $\mathrm{LDL} \leq 2,6 \mathrm{mmol} / \mathrm{L}$ for primary prevention and $\leq 1,8 \mathrm{mmol} / \mathrm{L}$ for secondary prevention.

The approval of the local Ethics Committee was obtained.

\section{Statistical analysis}

Statistical version R 2.15.3 Software (R Foundation for Statistical Computing, Vienna, Austria) was used to perform the statistical analysis [11]. All data are presented as the arithmetic mean \pm standard deviation or as absolute and relative numbers. We used Chi square test for comparison of categorical data according to sex. Continuous variables were compared with t test and Mann-Whitney test. The zero hypothesis was tested with a significance threshold $\mathrm{p}<0.05$.

\section{Results}

The prevalence of T2DM among individuals between ages 35 and 90 years, was 11,84\%. Out of 531 patients whose records we investigated $50.5 \%$ were female. The mean age of the patients was $65,88 \pm 9,86$ years. The majority of them were between 60 and 69 years old. Table 1 shows clinical and laboratory characteristics of the study population. The mean value of HbAlc was $7,56 \pm 1,71$ and there was no significant difference between men and women $(\mathrm{p}=0,445)$.

Women had higher levels of SBP compared to men $(\mathrm{p}=0.003)$. Smoking categories differed by gender $(\mathrm{p}<0.001)$, in the female population non-smokers were dominant. Women also had significantly higher levels of $\mathrm{TC}(\mathrm{p}<0,001)$ as well as levels of HDL and LDL $(\mathrm{p}=0.010$; $\mathrm{p}=0.013)$.

Table 1 Clinical and laboratory characteristic of the study population

\begin{tabular}{|c|c|c|c|c|}
\hline Characteristics (n, \%) & $\begin{array}{c}\text { Total } \\
(\mathrm{n}=531)\end{array}$ & $\begin{array}{c}\text { Men } \\
(n=263)\end{array}$ & $\begin{array}{l}\text { Women } \\
(\mathrm{n}=268)\end{array}$ & $\mathrm{p}$ \\
\hline Age (years) $\dagger$ & $65.88 \pm 9.86$ & $64.79 \pm 10.27$ & $66.95 \pm 9.41$ & $0.012^{1}$ \\
\hline \multicolumn{5}{|l|}{ Age group } \\
\hline $35-39$ & $5(0.9)$ & $3(1.1)$ & $2(0.7)$ & $0.662^{2}$ \\
\hline $40-49$ & $25(4.7)$ & $16(6.1)$ & $9(3.4)$ & \\
\hline $50-59$ & $93(17.6)$ & $53(20.2)$ & $40(15.0)$ & \\
\hline $60-69$ & $222(42.0)$ & $100(42.0)$ & $112(41.9)$ & \\
\hline $70-79$ & $139(26.3)$ & $57(21.8)$ & $82(30.7)$ & \\
\hline $80-89$ & $45(8.5)$ & $23(8.8)$ & $22(8.2)$ & \\
\hline Diabetes duration $(\geq 8$ years) & $272(52.0)$ & $127(49.0)$ & $145(54.9)$ & $0.421^{2}$ \\
\hline $\operatorname{HbA} 1 \mathrm{c}(\%)^{*}$ & $7.56 \pm 1.71$ & $7.53 \pm 1.70$ & $7.59 \pm 1,72$ & $0.445^{1}$ \\
\hline Hypertension & $456(85.9)$ & $219(83.3)$ & $237(88.4)$ & $0.088^{1}$ \\
\hline Systolic blood pressure $(\mathrm{mmHg}) \dagger$ & $142.03 \pm 18.77$ & $139.25 \pm 16.96$ & $144.87 \pm 20.11$ & $0.003^{1}$ \\
\hline Diastolic blood pressure $(\mathrm{mmHg}) \dagger$ & $84.23 \pm 9.51$ & $83.88 \pm 9.26$ & $84.59 \pm 9.78$ & $0.457^{1}$ \\
\hline Smokers & $87(32.8)$ & $48(36.6)$ & $39(29.1)$ & $0.250^{2}$ \\
\hline Ex-smokers & $45(17.0)$ & $34(26.0)$ & $11(8.2)$ & $<0.001^{2}$ \\
\hline Body mass index $(\mathrm{kg} / \mathrm{m} 2) \dagger$ & $29.67 \pm 5.57$ & $29.11 \pm 5.17$ & $30.22 \pm 5.90$ & $0.163^{3}$ \\
\hline Total cholesterol $(\mu \mathrm{mol} / \mathrm{L}) \dagger$ & $5.60 \pm 1.46$ & $5.29 \pm 1.21$ & $5.89 \pm 1.62$ & $<0.001^{3}$ \\
\hline Triglycerides $(\mathrm{mmol} / \mathrm{L}) \dagger$ & $2.28 \pm 1.36$ & $2.36 \pm 1.37$ & $2.21 \pm 1.34$ & $0.230^{3}$ \\
\hline HDL-cholesterol $(\mathrm{mmol} / \mathrm{L}) \dagger$ & $1.20 \pm 0.46$ & $1.14 \pm 0.44$ & $1.27 \pm 0.47$ & $0.010^{3}$ \\
\hline LDL-cholesterol $(\mathrm{mmol} / \mathrm{L}) \dagger$ & $3.29 \pm 1.26$ & $3.09 \pm 1.08$ & $3.48 \pm 1.38$ & $0.013^{3}$ \\
\hline
\end{tabular}

t test, ${ }^{2}$ Chi-squared test, ${ }^{3}$ Mann-Whitney test, $\uparrow$ Mean \pm standard deviation, ${ }^{*}$ Glycated haemoglobin. 
Prevalence of micro and macroangiopathic complications is shown in Table 2. There were no significant differences in the prevalence of neuropathy, retinopathy and nephropathy between men and women $(\mathrm{p}=1.000$; $\mathrm{p}=0,948 ; \mathrm{p}=0.842$ ) assessed by ICD code records. Taking into account levels of serum creatinine, number of patients with GFR between 30 and $89 \mathrm{~mL} / \mathrm{min}$ is 60.8 $\%$. Almost one third of patients had coronary artery disease and $18.1 \%$ had heart attack or stroke. Heart attack was more frequently observed in male patients while there was no difference between men and women regarding stroke $(p=0.046, p=0.455)$. Researchers got data also from National Health Insurance Fund about number of patients with history of acute myocardial infraction. Out of 14144 patients 1629 had heart attack which is $11.52 \%$ prevalence rate and in concordance with prevalence rate from our study sample $(11.4 \%)$.
Table 3 shows results of achieved treatment goals regarding glucoregulation and control of CVRF. Fiftynine percent of patients achieved optimal levels of HbAlc $(\leq 7 \%)$. Target levels of $\mathrm{SBP} \leq 140 \mathrm{mmHg}$ were more frequently attained by men $(\mathrm{p}=0.038)$, while there was not significant difference in attaining target $\mathrm{DBP} \leq 85 \mathrm{mmHg}$ between men and women $(\mathrm{p}=0.646)$. Obesity was more frequent among women $(\mathrm{p}=0.025)$. Significant difference between men and women in achieving target lipid levels was seen only in achieving $\mathrm{LDL} \leq 1.8 \mathrm{mmol} / \mathrm{L}$ which was more frequently observed in male population $(\mathrm{p}=0.039)$. In patients on primary prevention only $5.7 \%$ had met target levels of $\mathrm{HbA} 1 \mathrm{c} \leq 7 \%, \mathrm{BP} \leq 140 / 85 \mathrm{mmHg}$ and $\mathrm{LDL} \leq 2.6 \mathrm{mmol} / \mathrm{L}$ while on secondary prevention $(\mathrm{HbAl} \leq 7 \%$, $\mathrm{BP} \leq 140 / 85 \mathrm{mmHg}, \mathrm{LDL} \leq 1.8 \mathrm{mmol} / \mathrm{L}$ ) that number was even smaller $3.7 \%$.

Table 2 Prevalence of diabetes-related micro- and macroangiopathic complications, as assessed by ICD code records and laboratory data

\begin{tabular}{|c|c|c|c|c|}
\hline $\begin{array}{l}\text { Characteristics } \\
(\mathrm{n}, \%)\end{array}$ & $\begin{array}{c}\text { Total } \\
(\mathrm{n}=531)\end{array}$ & $\begin{array}{c}\text { Men } \\
(n=263)\end{array}$ & $\begin{array}{l}\text { Women } \\
(\mathrm{n}=268)\end{array}$ & $\mathrm{p}^{1}$ \\
\hline Retinopathy & $103(19.6)$ & $52(19.9)$ & $51(19.3)$ & 0.948 \\
\hline Neuropathy & $171(32.4)$ & $85(32.4)$ & $86(32.5)$ & 1.000 \\
\hline Nephropathy & $31(5.8)$ & $15(5.7)$ & $16(5.8)$ & 0.842 \\
\hline Creatinine $\mu \mathrm{mol} / \mathrm{L} \dagger$ & $83.61 \pm 35.94$ & $88.63 \pm 33.66$ & $78.09 \pm 37.63$ & $<0.001^{2}$ \\
\hline $\mathrm{GFR}^{3}\left(\mathrm{~mL} / \mathrm{min} / 1.73 \mathrm{~m}^{2}\right) \dagger$ & $76.91 \pm 21.21$ & $79.17 \pm 19.93$ & $74.43 \pm 22.34$ & $0.137^{2}$ \\
\hline GFR $<30$ & $10(3.2)$ & $3(1.8)$ & $7(4.6)$ & 0.213 \\
\hline $30<\mathrm{GFR}<60$ & $64(20.4)$ & 27 (16.6) & $37(24.7)$ & 0.263 \\
\hline GFR $>90$ & $124(39.2)$ & $69(41.6)$ & $55(36.7)$ & 0.120 \\
\hline Coronary artery disease & $158(30.3)$ & $79(30.5)$ & $79(30.0)$ & 0.887 \\
\hline Heart attack & $59(11.4)$ & $37(14.4)$ & $22(8.4)$ & 0.046 \\
\hline Heart attack with revascularisation & $34(6.4)$ & $22(8.4)$ & $12(4.8)$ & 0.098 \\
\hline Revascularisation without heart attack & $25(4.7)$ & $9(3.4)$ & $16(6.0)$ & 0.237 \\
\hline Stroke & $35(6.7)$ & $20(7.7)$ & $15(5.7)$ & 0.455 \\
\hline Peripheral artery disease & $67(12.8)$ & $37(14.3)$ & $30(11.4)$ & 0.394 \\
\hline Chronic heart failure & $50(9.6)$ & $26(10.0)$ & $24(9.2)$ & 0.848 \\
\hline At least one complication & $322(60.6)$ & $163(62.0)$ & $159(59.3)$ & 0.592 \\
\hline
\end{tabular}

${ }^{1}$ Chi-squared test, ${ }^{2}$ Mann-Whitney test, $\uparrow$ Mean \pm standard deviation, ${ }^{3}$ Glomerular filtration rate.

Table 3 Results of achieved treatment goals regarding glucoregulation and control of CVRF.

\begin{tabular}{|c|c|c|c|c|}
\hline Characteristics $\dagger$ & Total & Men & Women & $\mathrm{p}^{1}$ \\
\hline $\mathrm{HbA} 1 \mathrm{c} \leq 7 \% *$ & $314(59.1)$ & $159(60.5)$ & $155(57.8)$ & 0.599 \\
\hline Systolic blood pressure $\leq 140 \mathrm{mmHg}$ & $172(57.6)$ & $129(62.9)$ & $105(52.5)$ & 0.038 \\
\hline Diastolic blood pressure $\leq 85 \mathrm{mmHg}$ & $258(62.2)$ & $133(64.9)$ & $125(62.2)$ & 0.646 \\
\hline Body mass index $\leq 30 \mathrm{~kg} / \mathrm{m}^{2}$ & $124(54,9)$ & $67(63,2)$ & $57(47,5)$ & 0.025 \\
\hline Non-smokers $(\%)$ & $133(50.2)$ & $49(37.4)$ & $84(62.7)$ & $<0.001$ \\
\hline Total cholesterol $\leq 5.0 \mu \mathrm{mol} / \mathrm{L}$ & $154(29.0)$ & $86(32.7)$ & $68(25.4)$ & 0.078 \\
\hline Triglycerides $\leq 1.7 \mathrm{mmol} / \mathrm{L}$ & $162(30.5)$ & $77(29.3)$ & $85(31.7)$ & 0.606 \\
\hline HDL-cholesterol $\geq 1 \geq 1,2 \mathrm{mmol} / \mathrm{L}$ & $121(38.0)$ & $58(37.7)$ & $63(38.2)^{*}$ & 0.903 \\
\hline LDL-cholesterol $<1.8 \mathrm{mmol} / \mathrm{L}(\mathrm{n}=330)$ & $24(7.3)$ & $17(10.6)$ & $7(4.1)$ & 0.039 \\
\hline LDL-cholesterol $<2.6 \mathrm{mmol} / \mathrm{L}$ & $92(27.9)$ & $49(53.3)$ & $43(46.7)$ & 0.402 \\
\hline $\begin{array}{l}\text { Primary prevention: } \mathrm{HbA} 1 \mathrm{c} \leq 7 \% \text {, blood pressure } \leq \\
140 / 85 \mathrm{mmHg}, \mathrm{LDL} \text {-cholesterol } \leq 2.6 \mathrm{mmol} / \mathrm{L}\end{array}$ & $16(5.7)$ & $9(6.5)$ & $7(4.8)$ & 0.719 \\
\hline $\begin{array}{l}\text { Secondary prevention: } \mathrm{HbA} 1 \mathrm{c} \leq 7 \% \text {, Blood pressure } \\
\leq 140 / 85 \mathrm{mmHg} \text {, LDL-cholesterol } \leq 1.8 \mathrm{mmol} / \mathrm{L}\end{array}$ & $5(3.7)$ & $3(4.3)$ & $2(3.1)$ & 0.699 \\
\hline
\end{tabular}




\section{Discussion}

According to the report of the International Diabetes Federation (IDF) prevalence of diabetes in Montenegro for the age group from 20 to 79 years for 2017 is $12.8 \%$. Majority of them suffer from T2DM [12]. These data place Montenegro among countries with the highest prevalence rates in Europe. Our estimated prevalence for Podgorica, which is the capital of Montenegro, is similar. IDF also reports that diabetes prevalence is slightly higher in men than women and that age group 65-79 years has the highest prevalence of diabetes [12]. We also got similar data for gender and age distribution. For half of the patients, disease duration could not be estimated precisely because electronic records have been introduced since 2009. So, we couldn't conclude whether these patients had diabetes before 2009 and for how long.

Electronic records were also a good tool to evaluate the percent of diabetic patients with hypertension which is the common comorbid condition. Many observational studies in Europe have reported similar hypertension rates in patients with T2DM (above $75 \%$ ) [13]. Hypertension in patients with $\mathrm{T} 2 \mathrm{DM}$ quadruple $\mathrm{CV}$ risk and $\mathrm{BP}$ measured in office is good predictor of $\mathrm{CV}$ morbidity and mortality $[14,15]$. Therefore, ADA recommends that BP should be measured in diabetic patients routinely at every visit [6]. Mean values of SBP and DBP were slightly higher than in a methodologically similar study conducted in Spain [7]. Data about BMI and smoking habit were also similar like in Spanish study where women had significantly higher values of BMI $\left(30.5 \pm 5.6 \mathrm{~kg} / \mathrm{m}^{2}\right.$ women vs $28.8 \pm 4.3 \mathrm{~kg} / \mathrm{m}^{2}$ men, $\left.\mathrm{p}<0.005\right)$ and percent of smokers was higher among men (24\% of men vs $6.0 \%$ of women, $\mathrm{p}<0.005)$. Mean values of serum lipid levels in our study pointed to already known characteristic features of diabetic dyslipidemia. This includes high levels of plasma TG, low levels of HDL and increased concentration of LDL [16]. Elevated LDL levels represent independent risk factor for CVD and major target for its prevention. According to meta-analysis that included data from 18686 diabetic patients reduction of LDL per $1 \mathrm{mmol} / \mathrm{L}$ resulted in $9 \%$ reduction of all cause mortality [17]. Framingham Study showed that there was no significant difference in the prevalence of elevated LDL levels among diabetic and non-diabetic individuals, but other studies showed that there was gender difference in diabetic patients regarding lipid levels. Russo et al. conducted a large Italian study in which diabetic female patients had significantly higher levels of TC, HDL and LDL than male patients $(\mathrm{p}<0.000)$ [18]. Our study showed the same results regarding gender-related differences.

Mean level of $\mathrm{HbA1c}$ from our study was also comparable to that from other study whose objective was to asses prescribing trends and glycemic control in patients with T2DM in Catalonia (Spain) during 20072013. In this study, the level of HbA1c was around $7.2 \%$ with no significant difference across years suggesting that suboptimal glycemic control is a common problem [19]. We found that more than a half of our patients achieved target levels of HbA1c $\leq 7 \%$ (59.1\%) which is a good result compared to other countries where the percentage of patients who were not at target varied from $26 \%$ in the Netherlands up to $52 \%$ in Turkey [20]. Maintaining good glycemic control is very important because it reduces the risk of developing microvascular and macrovascular complications [21].

In current study, diabetic neuropathy was the most commonly reported among microvascular complications, while other studies suggest that diabetic retinopathy may be the most common microvascular complication with prevalence rates ranging from $25-40 \%[22,23]$. This may be explained by an inadequate diagnosis being entered into the medical records due to a lack of time, poor doctorpatient communication, etc. For the same reason, the number of patients with reported nephropathy is only $5.8 \%$ while the number of patients with impaired renal function and $\mathrm{GFR} \leq 60 \mathrm{ml} / \mathrm{min} / 1.73 \mathrm{~m}^{2}$ is $23.7 \%$ which is similar to the Spanish study (20\%) [7]. Data about macrovascular complications were more accurately entered in the medical records because the only way for patient to get certain medicines was to have adequate diagnosis on the recipe. Coronary heart disease was seen in almost one third of patients which is higher percentage compared to other European studies whose results varied from $11.3 \%$ to $16.2 \%[7,24]$. One of these studies was big Italian multicenter cohort study which enrolled 19468 patients with the aim to estimate the prevalence of coronary heart disease. The percentage of patients with heart attack $(4.5 \%$ of males vs $2.0 \%$ of females, $\mathrm{p}<0.0001$ ) was lower from that observed in our study $(14.4 \%$ of males vs $8.4 \%$ of females, $\mathrm{p}=0.046$ ).

The reason for higher percentage of coronary heart disease in our study could be poor control of cardiovascular risk factors. We found that glycemic control, as well as control of blood pressure did not differ much from other studies whereas lipid control was harder to achieve. In other studies the number of patients who achieved target $\mathrm{LDL} \leq 1.8 \mathrm{mmol} / \mathrm{L}$ varied from $37.9 \%$ to $56.2 \%$, while more than two thirds $(72.4 \%)$ achieved LDL $\leq 2.6 \mathrm{mmol} / \mathrm{L}$ [7,25]. According to National Health and Nutrition Examination Survey data from 2007-2010, $18.8 \%$ of diabetic patients achieved all three goals, while in the Spanish study that number was $25 \%$ [7,26]. Disappointingly, a small proportion of patients in our study met all three goals in primary $(5.7 \%)$ and in secondary prevention $(3.7 \%)$. Some of the reasons for inadequate treatment of dyslipidemia could lie with reluctance among physicians to intensify treatment and with patients not complying with the regimen because they have to pay for some of the drugs (statins). Concerning the fact that LDL plays a central role in the pathogenesis of CVD, more aggressive control of this modifiable risk factor is needed alone, as well as in combination with glycemic and blood pressure control.

Our study has several strengths and limitations. To the best of authors' knowledge this is the first study 
that investigates control of glycaemia and CVRF in patients with T2DM in Montenegro. Another important strength derives from inclusion of data from primary care database that are closer to the real-life than data from randomized clinical trials which have strictly controlled conditions. Retrospective design and incomplete medical records represent main limitations. That is why some of the diabetes-related complications (microvascular complications) were underreported and its real prevalence could not be estimated.

\section{References}

1. Tamayo T, Resenbauer J, Wild SH, Spijkerman AM, Baan C, Forouhi NG et al. Diabetes in Europe: an update. Diabetes Res Clin Pract 2014; 103(2):206-217.

2. Forouhi NG, Wareham NJ. Epidemiology of diabetes. Medicine (Abingdon) 2014; 42(12):698-702.

3. Heydari I, Radi V, Razmjou S, Amiri A. Chronic complications of diabetes mellitus in newly diagnosed patients. Int J Diabetes Melit 2010, 2(1):61-63.

4. Bertoluci MC, Rocha VZ. Cardiovascular risk assessment in patients with diabetes. Diabetol Matab Syndr 2017; 9:25.

5. Centers for Disease Control and Prevention. National diabetes statistics report: Estimates of diabetes and its burden in the United States, 2014. Atlanta, GA: US Department of Health and Human Services; 2014.

6. American Diabetes Association. Standards of Medical Care in Diabetes - 2017. Diabetes Care 2017; 40(Suppl. 1):S75-S87.

7. Vinagare I, Mata-Cases M, Hermosilla E et al. Control of glycemia and cardiovascular risk factors in patients with type 2 diabetes in primary care in Catalonia (Spain). Diabetes Care 2012; 35(4): 774-9.

8. American Diabetes Association. Promoting Health and Reducing Disparities in Populations. Diabetes Care 2017; 40(Suppl. 1): S6-S10.

9. National Kidney Foundation. GFR calculator. Available at: https://www.kidney.org/professionals/kdoqi/gfr_calculator

10. Piepoli MF, Hoes AW, Agewall S et al. 2016 European Guidelines on cardiovascular disease prevention in clinical practice: The Sixth Joint Task Force of the European Society of Cardiology and Other Societies on Cardiovascular Disease Prevention in Clinical Practice (constituted by representatives of 10 societies and by invited experts) Developed with the special contribution of the European Association for Cardiovascular Prevention \& Rehabilitation (EACPR). Eur Heart J 2016; 37:2315-2381.

11. $\mathrm{R}$ development core team $\mathrm{R}$ : a language and enviroment for statistical computing. R foundation for statistical computing, Vienna, Austria, 2011.

12. International Diabetes Federation. IDF Diabetes Atlas, 8th edn. Brussels, Belgium: International Diabetes Federation, 2017. Availible at: http://www.diabetesatlas.org

13. Colosia AD, Palencia R, Khan S. Prevalence of hypertension and obesity in patients with type 2 diabetes mellitus in observational studies: a systematic literature review. Diabetes Metab Syndr Obes $2013 ; 6: 327-38$

\section{Conclusion}

Our study showed high prevalence of T2DM in Montenegro. This represents significant burden for our health care system especially due to the large number of complications that diabetes carries with itself. Good control of the disease can prevent many of these complications but according to a large number of studies this still remains a challenge. In the current study the number of diabetic patients with coronary heart disease was higher compared to other European studies. Also, control of HbAlc and blood pressure was similar to other studies but reaching target levels of LDL was challenging for our patients. Further analyses are needed in order to discover the reasons for poor control of certain CVRF and to develop strategies for its optimal management.

14. Martín-Timón I, Sevillano-Collantes C, Segura-Galindo A, Javier del Cañizo-Gómez F. Type 2 diabetes and cardiovascular disease: Have all risk factors the same strength? World J Diabetes 2014; 5(4):444-70.

15. Parati G, Ochoa JE, Salvi P, Lombardi C, Bilo G. Prognostic Value of Blood Pressure Variability and Average Blood Pressure Levels in Patients With Hypertension and Diabetes. Diabetes Care 2013; 36(Suppl 2):S312-324.

16. Mooradian AD. Dyslipidemia in tpe 2 diabetes mellitus. Nat Clin Pract Endocrinol Metab 2009; 5(3):150-9.

17. Chehade JM, Gladysz M, Mooradian AD. Dyslipidemia in type 2 diabetes: prevalence, pathophysiology, and management. Drugs 2013; 73(4):327-39.

18. Russo G, Pintaudi B, Giorda C et al. Age- and gender-related differences in LDL-cholesterol management in outpatients with type 2 diabetes mellitus. Int J Endocrinol 2015; 2015:957105.

19. Mata-Cases M, Franch-Nadal J, Real J, Maurico D. Glycaemic control and antidiabetic treatment trends in primary care centres in patients with type 2 diabetes mellitus during 2007-2013 in Catalonia: a population-based study. BMJ 2016; 6(10): e012463.

20. Blonde L, Aschner P, Bailey $\mathrm{C}$ et al. Gaps and barriers in the control of blood glucose in people with type 2 diabetes. Diab Vasc Dis Res 2017; 14 (3):172-83.

21. Litwak L, Goh SY, Hussein Z, Malek R, Prusty V, Khamseh ME. Prevalence of diabetes complications in people with type 2 diabetes mellitus and its association with baseline characteristics in the multinational A1chieve study. Diabetol Metab Syndr 2013;5(1):57.

22. Fowler M. Microvascular and Macrovascular Complications of Diabetes. Clinical Diabetes 2008; 26(2):77-82.

23. Ting DSW, Cheung GCM,Wong T Y. Diabetic retinopathy: global prevalence, major risk factors, screening practices and public health challenges: a review. Clinical \& Experimental Ophthalmology 2016; 44:260-77.

24. DAI Study Group. The prevalence of coronary heart disease in Type 2 diabetic patients in Italy: the DAI study. Diabet Med 2004; 21(7): 738-45.

25. Corriere MD, Minang LB, Sisson SD, Brancati FL, Kalyani RR. The use of clinical guidelines highlights ongoing educational gaps in physicians' knowledge and decision making related to diabetes. BMC Med Educ 2014; 14:186.

26. Stark Casagrande S, Fradkin JE, Saydah SH, Rust KF, Cowie CC. The prevalence of meeting A1C, blood pressure, and LDL goals among people with diabetes 1988-2010. Diabetes Care 2013; 36(8): 2271-9. 